\title{
The benefit mindset: The psychology of contribution and everyday leadership
}

\author{
Ashley Buchanan · Margaret L. Kern
}

\begin{abstract}
This paper explores the significance of mindset in shaping a future of greater possibility. One's mindset reflects personally distinguishable attitudes, beliefs and values, which influence one's ability to learn and lead, and to achieve and contribute. Bringing together two areas of research - a "being well" perspective from positive psychology and a socially and ecologically orientated "doing good" perspective - the Benefit Mindset is presented as a mutually supportive model for promoting wellbeing on both an individual and a collective level. It builds upon Dweck's Fixed and Growth Mindset theory, by including the collective context in which an individual resides. The Benefit Mindset describes everyday leaders who discover their strengths to make valuable contributions to causes that are greater than the self, leaders who believe in making a meaningful difference, positioning their actions within a purposeful context. We argue that creating cultures of contribution and everyday leadership could be one of the best points of leverage we have for simultaneously bringing out the best in people, organizations and the planet.
\end{abstract}

Keywords: mindset, contribution, leadership, learning, success, purpose, wellbeing, social innovation, systems thinking

\section{Introduction}

When Carol Dweck's book, Mindset: The New Psychology of Success (2006), was first published, it was promoted as a simple idea that made a big difference. Dweck suggested that beliefs about our own intelligence and abilities - as either fixed traits that we cannot change or as attributes that can be improved through effort - have an important influence on our ability to learn and grow. According to this Fixed and Growth Mindset (FGM) theory, a Fixed Mindset leads to a reduced capacity for learning, whereas a Growth Mindset offers a pathway for reaching higher levels of human potential. This concept has become popular in education and business, suggesting that the mindset we choose to adopt for ourselves profoundly shapes our ability to learn and to be successful (Harvard Business Review Staff, 2014).

Ten years on, however, we live in a world that is starting to question what it means to grow and be successful (Honeyman, 2014). Humanity is facing an ever-increasing number of pressing social, environmental, and economic challenges, including degenerating ecosystems, population growth, and economic stress (Scharmer \& Kaufer, 2013). There is increasing appreciation for the indivisible and interconnected nature of our wellbeing (Ki-Moon, 2012), and the need for setting limits to economic and population growth on a planet with finite resources (Capra \& Luisi, 2014; Meadows, Meadows, \& Randers, 1992).

It is in this context that a new socially and environmentally focused mindset paradigm appears to be on the rise. Rather than being driven by individual gain, this emerging mindset and global movement is symbolized by people who believe in being well (Rusk \& Waters, 2013), 
and doing good for our world (Hawken, 2007). It is a purpose-driven, leadership-based mindset that is redefining success: not only being the best in the world, but also being the best for the world. It is what we call the Benefit Mindset.

To support this position, we first consider mindset theory from an individual and a collective perspective. We recognize both the contribution that FGM has provided to our understanding of learning and achievement, as well as its limitations in addressing our collective challenges. Second, we suggest that individually focused "being well" perspectives coming from positive psychology complement the leadership and purpose focused "doing good" applications coming from socially and environmentally oriented communities and organizations. Finally, we propose the Benefit Mindset - which is orientated towards collectively creating the future - as a complementary evolution of FGM.

\section{Mindset theory}

Mindset can generally be defined as the underlying assumptions that shape a person's ability to perceive and understand the world (McEwen \& Schmidt, 2007). Mindset is a deep psychological construct that underpins our personally distinguishable attitudes, beliefs, and values (Schein, 2015). It influences our "everyday" behaviors and actions (Senge, 1990), our ability to learn (Dweck, 2006), and has a cascading, self-fulfilling effect on reality (Crum et al., 2011; Crum \& Langer, 2007). This means that there is no way to avoid the subconscious influence of our mindset (Bohm \& Edwards, 1999). The mindset we adopt for ourselves acts like a puppet master, pulling the "everyday" strings of our future possibilities on both individual and a collective levels (Clifton, 2013).

With appropriate ability and conditions, we can consciously shift our mindsets. At an individual level, creating shifts in our mindset and beliefs can promote long-term improvements in wellbeing and resilience (e.g., Vella-Brodrick, 2013). Personal shifts also impact outcomes at the collective level. Indeed, Meadows (1999) suggested that the most powerful and influential whole-system lever is the mindset out of which a system arises. She states that mindsets are the underlying sources of systems, and small shifts in our mindsets can produce big systemic changes. Thus, mindset is an individual characteristic that offers great potential at creating change at both individual and collective levels. Being able to co-discover how mindsets manifest themselves, while being open and able to shift them, is the essence of creating profound personal and whole-system change (Brown, 2005; Hochachka, 2005; Scharmer, 2009).

Although mindset has been studied by numerous scholars across multiple disciplines (e.g, McEwen \& Schmidt, 2007; Meadows, 1999; Schein, 2015), Dweck's FGM theory has received the most attention within various sub-disciplines of psychology. Dweck's mindset research specifically focuses on how beliefs around the nature of one's intelligence impacts a person's ability to learn, accomplish their goals, and reach their potential (Dweck, 2006). By limiting the theory's focus to beliefs on intelligence and learning, it has enabled numerous studies on the relationship between mindset and accomplishment. However, this limited focus generally neglects the broader contextual implications of mindset.

The major implication of this limited focus is that it overly encourages people to think about what they do (Fixed Mindset) and how they do it (Growth Mindset), rather than the broader question of why they do something. This leads to a tendency for individuals to repeat the patterns of the past, rather than bringing about what could be different and meaningful in the world.

In effect, Dweck's framework has isolated learning and accomplishment from the broader context of leadership and purpose. Given that today's modern pursuit of success and growth is believed to be one of the main reasons for the global challenges we are facing in the world today 
(Capra \& Luisi, 2014), any framework that promotes learning and accomplishment without context is arguably a risky endeavor. By not specifically considering the larger socioenvironmental context, the FGM framework runs the risk of creating unintended consequences for our common future. From a societal perspective, rather than promoting "learning for learning's sake" and "accomplishment for accomplishment's sake," it is preferable to have a mindset framework that encourages people to think about why they do what they do, and how they can make valuable contributions to the collective good.

This is not to say that learning and the pursuit of accomplishment should not be encouraged. The human drive to learn, achieve and realize our visions is one of the most powerful tools we have for creating the future (e.g., Ryan \& Deci, 2000). However, if we want to create the best future possibility for all of humanity, then such motivations should be situated within a purposeful and collective context (Clifton, 2015; Cooperrider \& Whitney, 2005).

\section{Moving beyond the FGM}

Over the past few decades, three areas of research and application have emerged that are enriching what it means to reach one's potential, and more explicitly positioning an individual's development and contributions within a purposeful and collective context. These are the being well movement, the doing good movement, and the leadership maturity framework.

\subsection{The being well movement}

Under the umbrella of positive psychology, there is growing interest in what could be called the being well movement. The field seeks to explore what is right with people, to identify activities and interventions that build a personal sense of wellbeing, and to gain a more scientifically rigorous picture of what constitutes the optimal functioning of individuals, groups, and institutions (Boniwell, 2012; Seligman \& Csikszentmihalyi, 2000). Core to this perspective is understanding the psychological traits that empower people to operate at the peak of their potential, such as discovering their strengths (e.g., Park, Peterson, \& Seligman, 2004), experiencing and sharing positive emotions (e.g., Fredrickson, 2004), participating in satisfying relationships (e.g., Gottman \& Silver, 2015), being psychologically engaged and interested in life tasks (e.g., Csikszentmihalyi, 1990), and having a sense of meaning and purpose in life (e.g., Steger et al, 2008).

Whereas early scholarship focused primarily on hedonic wellbeing (i.e., feeling good, with a focus on emotion), the past decade has increasingly seen a shift toward more sophisticated models of wellbeing (e.g., Huppert \& So, 2013; Ryff \& Singer, 1998; Seligman, 2012). Notably, although much of the focus has been on individual subjective wellbeing, there is a growing call to turn to more collective and whole system conceptualizations (e.g., Boston Consulting Group, 2015; Ki-Moon, 2012). Studies are increasingly considering wellbeing in the workplace (e.g., Cameron \& Dutton, 2003), in schools (e.g., Oades, Robinson, \& Green, 2011; Waters \& White, 2015), and in communities (e.g., Cooperrider \& Fry, 2012; Seligman, 2013).

One of the goals of this movement is to see a greater proportion of the world's population flourishing (e.g., Seligman, 2012). The pursuit of this goal is leading to the realization that human flourishing is best thought of, not as an individual activity, but rather, as something we must do together (e.g., Ki-Moon, 2012). This goal must be approached on both an individual and a collective level if we want to live in a flourishing global society. As a result, this being well movement is fundamentally enriching our appreciation of what it means to reach our potential beyond learning and achievement, and it is helping populations widen their circle of compassion to encompass our collective ability to flourish. 


\subsection{The doing good movement}

What if the aim of every person, every organization, and every act of development was to be a force for good? In what is being called the doing good movement (Hawken, 2007), companies, communities, policies, and several areas of study are doing just that. International groups such as B-Corporation (Honeyman, 2014) and Conscious Capitalism (Mackey \& Sisodia, 2014) have been helping organizations all over the world return shareholder value and purposefully benefit the common good (Felbe, 2015; Sisodia, Sheth, \& Wolfe, 2014). Practices such as Social Labs (Hassan, 2014) and Collective Impact (Kania \& Kramer, 2011) are helping communities facilitate large-scale social change and improvements. At the highest level, policies and measures like the Global Goals (www.globalgoals.org) have been developed to guide everyone towards a sustainable future.

At the heart of this doing good movement are people leading with purpose (Hurst, 2014), people who share a deep motivation to be of value to the systems to which they belong (Edwards, 2015; Brown, 2011). These leaders believe in making generative contributions to society, the environment, and the economy - thinking about me and we (Hollender, 2015; Scharmer \& Kaufer, 2013).

What is becoming clear to the leaders of this movement is that it is not enough to address doing good through externally focused initiatives alone. In order to change the world externally, we need to be also willing to change ourselves internally by shifting our mindsets (e.g., Bohm \& Edwards, 1991; Reed, 2007; Scharmer, 2009). In particular, it has been suggested that we need to cultivate a willingness to work collectively, learning how to access a deeper level of our humanity (Heifetz, Grashow \& Linsky, 2009; Scharmer \& Kaufer, 2013), from being learners and achievers who are focused on doing things better to being leaders and contributors who are focused on doing better things.

In summary, this doing good movement aspires to provide people with a richer appreciation of what it means to be of value - to themselves, to others, to nature and to the future.

\subsection{The Leadership Maturity Framework}

A third area that is enriching what it means to reach one's potential, and positions an individual's development within a collective context, is the human development literature. Building on Ego Development Theory (Loevinger, 2014), the Leadership Maturity Framework (LMF; CookGreuter, 2013) describes different ways that adults make meaning at different levels of developmental maturity (see Table 1 below). As a person matures, their meaning-making approach, their mindset, and their action logic becomes more comprehensive and effective in dealing with the complexities of life (Rooke \& Torbert, 2005).

The Fixed and Growth Mindsets can generally be seen to parallel the expert and achiever levels of leadership maturity, respectively. Achievers have typically been found to only be able to work within the systems to which they belong and do not question the system itself. However, the framework identifies higher levels of meaning-making maturity; this includes the individualist and the strategist. The theory suggests that it is only when people mature to an individualist level of leadership maturity that they can regularly maintain ecosystem awareness and can lead the systems they are a part of, rather than just learn and achieve within the system. Thus, individualists have a significant advantage for questioning why they do what they do, challenging their underlying assumptions, and finding purpose beyond the accomplishment of goals. Making the shift from achiever to individualist thus represents the beginning of a shift from being a learner and an achiever within a system to becoming a leader for the system. 
Table 1. Leadership Maturity Framework: Expert to strategist levels of leadership maturity

\begin{tabular}{|c|c|c|}
\hline Maturity & $\%$ & Key Characteristics \\
\hline Strategist & $4 \%$ & $\begin{array}{l}\text { - Embraces the tenets of an ecosystem worldview } \\
\text { - Develops lifetime purpose } \\
\text { - Committed to creating ecosystem benefit } \\
\text { - Generates organizational and personal transformations }\end{array}$ \\
\hline Individualist & $10 \%$ & $\begin{array}{l}\text { - } \quad \text { Able to shift from ego to ecosystem awareness } \\
\text { - } \quad \text { Looks at the status quo through multiple perspectives } \\
\text { - } \quad \text { Able to query their assumptions, values and beliefs } \\
\text { - } \quad \text { Before solving problems, figures out what the problem is }\end{array}$ \\
\hline Achiever & $30 \%$ & $\begin{array}{l}\text { - Goal and ideal oriented } \\
\text { - Continues to grow and develop themselves } \\
\text { - Often questions the "shoulds" in professional contexts } \\
\text { - Independent, entrepreneurial and self-reliant }\end{array}$ \\
\hline Expert & $38 \%$ & $\begin{array}{l}\text { - Interested in being successful } \\
\text { - } \quad \text { Ruled by logic and expertise } \\
\text { - Has a strong sense of what "should" and "ought" to be } \\
\text { - Likes to perfect their craft }\end{array}$ \\
\hline
\end{tabular}

Note: Levels are organized hierarchically, with greater maturity at the top level (strategist) versus bottom (expert). Percentages of sample population by Rooke \& Torbert, (2005). Characteristics noted by CookGreuter, (2013). This table is only a partial reproduction of the LMF. For the complete table, refer to CookGreuter and Rooke \& Torbert.

The potential for learning and leadership increases again once people shift to the strategist level of maturity. Strategists are able to hold a world-centric perspective. They tend to focus on developing a lifetime purpose, have been shown to be highly effective at leading organizational and societal transformations (Brown, 2011), and generally commit to making a meaningful difference for all of their stakeholders.

As a whole, the LMF highlights that reaching a world-centric perspective is the result of internal growth and transcendence (Esbjörn-Hargens, 2009), and that there are definable and testable mindsets that are consistent with the FGM as well as the emerging being well and doing good movements.

\section{The Benefit Mindset}

To reflect this emerging mindset paradigm, we propose an extension to the FGM framework: The Benefit Mindset (Figure 1 below). The Benefit Mindset framework highlights some of the important distinctions we have noted: between learning and leadership, and between achievement and contribution. The definition specifically includes the term "everyday" because of the ever-present puppet master effect our mindsets have on the lives we lead, the actions we take, and the future possibilities of the world we live in. As a practical example, Figure 2 below provides a case study of an everyday leader. 
Figure 1. Comparing the Fixed, Growth and Benefit Mindsets

Fixed

MINDSET

Everyday experts who seek perfection and avoid failure

Focus on reproducing what they know

Believes their strengths are innate gifts that can't be developed and focus on perfecting their abilities.
Growth MINDSET

Everyday learners who seek growth and development

Focus on improving how they do what they do

Believes their strengths can be developed with effort, reaching higher levels of achievement and ability.
Benefit

MINDSET

Everyday leaders who seek

to 'be well' and 'do good'

Focus purposefully on

why they do what they do

Believes in developing their strengths and meaningfully contributes to a future of greater possibility.

Figure 2. Marva Collins: An everyday leader case study (adapted from Roberts, 2015)

Marva Collins is an American teacher who was raised with the "expectation to be excellent." However, in the 1970s, she worked in a school system where the inadequacies associated with African-American education appalled her. Marva lived at a time when students were labelled as "unteachable" or as having impossible-to-overcome learning disabilities if they did not fit into the normal education system. Whereas most teachers tried to get the most out of this existing system, Collin's questioned the purpose of the system itself. She decided to put her values in action, cashed in her $\$ 5,000$ pension, and started a new school for any child who'd been failed by the school system. The school was especially for those diagnosed with impossible-to-overcome learning disabilities. Facing tough odds, she learned to embody her value of "believing in the children" and famously transformed the lives of thousands of underprivileged students. After the first year, every student in her class tested five grade levels higher. Collins not only taught the unteachable, she inspired a whole new generation of teachers. In 1980, Ms. Collins was recognised for her contributions, being asked to become the Secretary of Education in the U.S. Government.

This proposed evolution is not to suggest that concepts such as the FGM are less important. On the contrary, learning how to grow, achieve and differentiate ourselves through deliberate practice is integral to every person's development. The Benefit Mindset simply positions human development and effort within a collective and purposeful context. By explicitly extending the FGM framework in this way, we provide a richer definition of what it means to learn and lead to achieve and collectively contribute.

From this perspective, the key question these everyday leaders ask themselves is not how they can flourish in isolation, but rather, how we can all come together and become partners in each other's flourishing. They recognize that our ability to flourish is deeply interrelated with the communities and ecosystems to which we belong. 
Finally, there is an interesting dynamic that can be seen here that is worth discussing. Although studies and applications across the being well and doing good movements have occurred in different domains, we suggest that the two are mutually supportive. The more well you are, the greater your capacity for doing good. And the more good you do, the greater your capacity for being well. Being well and doing good are quite likely interconnected enablers of each other. The existence of such a virtuous relationship is supported by numerous findings, including theories of resilience (Reivich \& Shatté, 2002), self-determination theory (Ryan \& Deci, 2000) the benefits of altruism (Post, 2005; Ricard, 2015), and post-ecstatic growth theory (Roepke, 2013).

\section{Implications}

The great value we see in this extension of the FGM is in how it can help people think about the interwoven nature of human and ecological flourishing. The Benefit Mindset is a powerful tool for talking about the role that mindset plays in purposefully creating the future. It is something anyone can do, regardless of position or status, to make a meaningful difference.

Additionally, this extension to the FGM has implications across multiple fields, most notably education, business and psychology, which we offer as a few examples, but encourage readers to consider specific applications to their own respective domains.

\subsection{Education}

Many education systems globally are over-emphasizing academic performance, and often neglect the potential of internal development (e.g., Palmer, Zajonc, \& Scribner, 2010). The Benefit Mindset framework provides students with a richer perspective of human potential and internal development. It can help students integrate learning and leadership, achievement and contribution at an early age. It also could have significant impacts in shifting students' awareness to include me and we, and in empowering youth to become purposeful future makers.

\subsection{Business}

It has been suggested that the future belongs to businesses with purpose (Honeyman, 2014; Hurst, 2014). Developing everyday leaders with a Benefit Mindset could be one of the best ways to truly embed purpose and everyday leadership into business operations. A growing number of people only want to work for purpose-driven organizations (Bailey, 2015), and the Benefit Mindset offers strategic value for attracting and supporting the development of people in using business as a force for good and in promoting cultures of human flourishing.

\subsection{Psychology}

Much of psychology focuses on what is within the person or on how aspects of the social context influence a person's behavior. The Benefit Mindset challenges psychologists to develop more sophisticated contextual perspectives of wellbeing, leadership, and human potential. It also challenges researchers to explore psychological pathways for shifting mindsets beyond growth. While there is clarity on how to shift from a Fixed to Growth Mindset, how do we help individuals and organizations cultivate a Benefit Mindset?

\section{Further work}

This paper is just the beginning of a broader conversation on the importance of mindset in shaping a future of greater possibility, and further research is needed to develop the thesis presented in this paper. 
We offer a challenge to the social sciences to explore the potential of the Benefit Mindset. Research questions could include: How does contribution impact individual wellbeing and promote collective flourishing? How does mindset empower people to widen their circle of compassion? What are the enablers and barriers to developing a Benefit Mindset? How might a school, business or sustainability project benefit from purpose-driven mindset development? What are the broader economic, societal, and ecological implications of a culture of contribution and everyday leadership? Does the level of application (e.g., individual, organizational, societal) influence outcomes? How do we best measure and quantify the scale and quality of benefit created?

While "being well" and "doing good" may sound reasonable, the words "well" and "good" involve a value judgment. How do we decide what "well" and "good" are? If it is beneficial to humanity, then people ought to be a part of defining what that well and good are. This level of moral and ethical complexity creates the need for dialogue between an increasing diversity of stakeholders. In addition, the definition of "benefit" may evolve over time and across cultures, depending upon the morals and values of the people themselves. Further work around cultural interpretations and definitions of the Benefit Mindset is needed.

\section{Conclusion}

While we can aspire to create a future of greater possibility, there is a case to be made that it is only going to be systemically possible if we also consider the ever-present influence of mindset. The Benefit Mindset is presented as a complementary evolution of Dweck's Fixed and Growth Mindsets, highlighting the important distinctions between learning and leadership, and between achievement and contribution. We argue that creating cultures of the Benefit Mindset could be one of the best points of leverage we have for simultaneously bringing out the best in people, organizations, and the planet as a whole. We hope that by defining this mindset paradigm, it will improve our collective understanding and provide psychological visibility of how our everyday leaders are creating profound personal and whole systems change.

\section{Authors}

Ashley Buchanan

Cohere

ash.buchanan@cohere.com.au

Margaret L. Kern

The University of Melbourne

peggy.Kern@unimelb.edu.au

\section{Publishing Timeline}

Received 9 June 2016

Accepted 23 November 2016

Published 9 June 2017

\section{References}

Bailey, M. (2015, November 17). It's hip to B corp, but it's not exactly legal [Blog post]. BRW Online. http://www.brw.com.au/p/business/it hip to corp but it not exactly pxNrSMQutaOqd8oqkNNim $\underline{\mathrm{K}}$ 
Ban, K-M. (2012). Secretary-General's remarks at high level meeting on "Happiness and well-being: Defining a new economic paradigm." http://www.un.org/sg/STATEMENTS/index.asp?nid=5966

Beal, D., Rueda-Sabater, E., \& Heng, S. L. (2015). Why well-being should drive growth strategies: The 2015 sustainable economic development assessment. Boston Consulting Group. https://www.bcgperspectives.com/content/articles/public-sector-sustainability-2015-sustainableeconomic-development-assessment/

Bohm, D., \& Edwards, M. (1991). Changing consciousness: Exploring the hidden source of the social, political and environmental crises facing our world. San Francisco, CA: Harper Collins.

Boniwell, I. (2012). Positive psychology in a nutshell: The science of happiness. London, United Kingdom: McGraw-Hill Education.

Brown. B. C. (2005). Theory and practice of integral sustainable development. Part 2: Values, developmental levels, and natural design. AQAL Journal of Integral Theory and Practice, 1(2), 2-39.

Brown, B. C. (2011). Conscious leadership for sustainability: How leaders with a late-stage action logic design and engage in sustainability initatives (Doctoral dissertation). Fielding Graduate University. Proquest Dissertations \& Theses (Accession Order No. 3498378).

Cameron, K. S., Dutton, J. E., \& Quinn, R. E. (2003). Positive organizational scholarship: Foundations of a new discipline. San Francisco, CA: Berrett-Koehler.

Capra, F. (1996). The web of life: A new scientific understanding of living systems. New York, NY: Anchor.

Capra, F., \& Luisi, P. L. (2014). The systems view of life: A unifying vision. Cambridge, United Kingdom: Cambridge University Press. https://doi.org/10.1017/CBO9780511895555

Clifton, J. (2013). Thirteen universal assessments which may contribute to the 'good life' (Unpublished masters thesis). University of Pennsylvania. Scholarly Commons. http://repository.upenn.edu/cgi/viewcontent.cgi?article=1041\&context=mapp capstone

Clifton, J. (2015). Positive psychology. http://jerclifton.com/positive-psych-faqs/

Cook-Greuter, S. (2013). Nine levels of increasing embrace in ego development: A full-spectrum theory of vertical growth and meaning making. Zugriff am, 18, 2015.

Cooperrider, D. L., \& Fry, R. (2012). Mirror flourishing and the positive psychology of sustainability. Journal of Corporate Citizenship, 46, 3-12. https://doi.org/10.9774/gleaf.4700.2012.su.00002

Cooperrider, D. L., \& McQuaid, M. (2012). The positive arc of systematic strengths: How appreciative inquiry and sustainable designing can bring out the best in human systems. Journal of Corporate Citizenship, 46, 71-102. https://doi.org/10.9774/GLEAF.4700.2012.su.00006

Cooperrider, D., \& Whitney, D. D. (2005). Appreciative inquiry: A positive revolution in change. San Francisco, CA: Berrett-Koehler.

Crum, A. J., Corbin, W. R., Brownell, K. D., \& Salovey, P. (2011). Mind over milkshakes: Mindsets, not just nutrients, determine ghrelin response. Health Psychology, 30(4), 424-429. https://doi.org/10.1037/a0023467

Crum, A. J., \& Langer, E. J. (2007). Mind-set matters: Exercise and the placebo effect. Psychological Science, 18(2), 165-171. https://doi.org/10.1111/j.1467-9280.2007.01867.x

Csikszentmihalyi, M. (1990). Flow: The psychology of optimal experience. New York, NY: Harper \& Row.

Duke, N. N., Skay, C. L., Pettingell, S. L., \& Borowsky, I. W. (2009). From adolescent connections to social capital: Predictors of civic engagement in young adulthood. Journal of Adolescent Health, 44(2), 161168. https://doi.org/10.1016/j.jadohealth.2008.07.007

Dweck, C. S. (2006). Mindset: The new psychology of success. New York, NY: Random House.

Dweck, C. S. (2007). Boosting achievement with messages that motivate. Education Canada, 47(2), 6-10.

Edwards, A. R. (2015). The heart of sustainability: Restoring ecological balance from the inside out. Gabriola Island, BC: New Society.

Esbjörn-Hargens, S. (2009). Integral ecology: Uniting multiple perspectives on the natural world. Boston, Massachusetts: Shambhala.

Felbe, C. (2015). Change everything: Creating an economy for the common good. London, England: Zed Books. Fredrickson, B. L. (2004). The broaden-and-build theory of positive emotions. Philosophical Transactions Royal Society of London Series B Biological Sciences, 1449, 1367-1378. https://doi.org/10.1098/rstb.2004.1512 
Furlong, M. J., Gilman, R., \& Huebner, E. S. (2014). Handbook of positive psychology in schools. (2nd ed.). London, England: Taylor \& Francis.

Gottman, J., \& Silver, N. (1999). The seven principles for making marriage work: A practical guide from the country's foremost relationship expert. New York, NY: Harmony.

Harvard Business Review Staff (2014). How companies can profit from a "growth mindset." Harvard Business Review. https://hbr.org/2014/11/how-companies-can-profit-from-a-growth-mindset

Hassan, Z. (2014). The social labs revolution: A new approach to solving our most complex challenges. San Francisco, CA: Berrett-Koehler. https://doi.org/10.9774/gleaf.9781783531455 5

Hawken, P. (2007). Blessed unrest: How the largest movement in the world came into being, and why no one saw it coming. New York, NY: Penguin.

Heifetz, R. A., Grashow, A., \& Linsky, M. (2009). The practice of adaptive leadership: Tools and tactics for changing your organization and the world. Boston, MA: Harvard Business.

Hochachka, G. (2005). Developing sustainability, developing the self: An integral approach to international and community development. POLIS Project on Ecological Governance. Victoria, BC: University of Victoria.

Hollender, J. (2015). Net positive: The future of sustainable business. Stanford Social Innovation Review. https://ssir.org/articles/entry/net positive the future of sustainable business

Honeyman, R. (2014). The B Corp handbook: How to use business as a force for good. San Francisco, CA: Berrett-Koehler.

Huppert, F., \& So, T. (2013). Flourishing across Europe: Application of a new conceptual framework for defining well-being. Social Indicators Research, 110(3), 837-861. https://doi.org/10.1007/s11205-011$\underline{9966-7}$

Hurst, A. (2014). The purpose economy: How your desire for impact, personal growth and community is changing the world. Boise, Idaho: Elevate.

Kania, J., \& Kramer, M. (2011). Collective impact. Stanford Social Innovation Review. https://ssir.org/articles/entry/collective impact

Laloux, F. (2014). Reinventing organizations: A guide to creating organizations inspired by the next stage of human consciousness. Brussels, Belgium: Nelson Parker.

Loevinger, J. (1970). Measuring ego development. San Francisco, CA: Jossey-Bass.

Mackey, J., \& Sisodia, R. (2014). Conscious capitalism, with a new preface by the authors: Liberating the heroic spirit of business. Boston, MA: Harvard Business.

McEwen, C. A., \& Schmidt, J. D. (2007). Leadership and the corporate sustainability challenge: Mindsets in action. SSRN 1118071. https://doi.org/10.2139/ssrn.1118071

Meadows, D. H. (1999). Leverage points: Places to intervene in a system. Hartland, VT: Sustainability Institute.

Meadows, D. H., Meadows, D. L., \& Randers, J. (1992). Beyond the limits: Global collapse or a sustainable future. London, England: Earthscan.

Oades, L. G., Robinson, P., \& Green, S. (2011). Positive education: Creating flourishing students, staff and schools. InPsych: The Bulletin of the Australian Psychological Society Ltd, 33(2), 16.

Palmer, P. J., Zajonc, A., \& Scribner, M. (2010). The heart of higher education: A call to renewal. New York, NY: John Wiley and Sons.

Park, N., Peterson, C., \& Seligman, M. E. (2004). Strengths of character and well-being. Journal of Social and Clinical Psychology, 23(5), 603-619. https://doi.org/10.1521/jscp.23.5.603.50748

Pittman, K., Irby, M., \& Ferber, T. (2001). Unfinished business: Further reflections on a decade of promoting youth development. In P. L. Benson \& K. J. Pittman (Eds.), Trends in youth development. (pp. 3-50). New York, NY: Springer. https://doi.org/10.1007/978-1-4615-1459-6 1

Post, S. G. (2005). Altruism, happiness, and health: It's good to be good. International Journal of Behavioral Medicine, 12, 66-77. https://doi.org/10.1207/s15327558ijbm1202 4

Reed, B. (2007). Shifting from 'sustainability' to regeneration. Building Research \& Information, 35(6), 674680. https://doi.org/10.1080/09613210701475753

Reivich, K., \& Shatté, A. (2002). The resilience factor: 7 essential skills for overcoming life's inevitable obstacles. New York, NY: Broadway Books. 
Ricard, M. (2015). Altruism: The power of compassion to change yourself and the world. New York, NY: Little, Brown and Company.

Roepke, A. M. (2013). Gains without pains? Growth after positive events. The Journal of Positive Psychology, 8(4), 280-291. https://doi.org/10.1080/17439760.2013.791715

Rooke, D., \& Torbert, W. R. (2005). Seven transformations of leadership. Harvard Business Review, 83(4), 66-76.

Rusk, R. D., \& Waters, L. E. (2013). Tracing the size, reach, impact, and breadth of positive psychology. The Journal of Positive Psychology, 8(3), 207-221. https://doi.org/10.1080/17439760.2013.777766

Ryan, R. M., \& Deci, E. L. (2000). Self-determination theory and the facilitation of intrinsic motivation, social development, and well-being. American Psychologist, 55(1), 68. https://doi.org/10.1037/0003$\underline{066 X .55 .1 .68}$

Ryff, C. D., \& Singer, B. (1998). The contours of positive human health. Psychological Inquiry, 9(1), 1-28. https://doi.org/10.1207/s15327965pli0901 1

Scharmer, C. O. (2009). Theory U: Learning from the future as it emerges. San Francisco, CA: Berrett-Koehler.

Scharmer, C. O., \& Kaufer, K. (2013). Leading from the emerging future: From ego-system to eco-system economies. San Francisco, CA: Berrett-Koehler.

Schein, S. (2015). A new psychology for sustainability leadership: The hidden power of ecological worldviews. Sheffield, UK: Greenleaf.

Seligman, M. (2012). Flourish: A visionary new understanding of happiness and well-being. New York, NY: Atria Books.

Seligman, M. (2013). Building the state of wellbeing: A strategy for South Australia. http://trove.nla.gov.au/work/188530971? selectedversion=NBD52321177

Seligman, M., Ernst, R., Gillham, K., Reivich, K., \& Linkins, M. (2009). Positive education: Positive psychology and classroom interventions. Oxford Review of Education, 35(3), 293-311. https://doi.org/10.1080/03054980902934563

Senge, P. (1990). The fifth discipline: The art and practice of the learning organization. New York, NY: Broadway Business.

Sisodia, R. S., Sheth, J. N., \& Wolfe, D. B. (2014). Firms of endearment: How world-class companies profit from passion and purpose. Upper Saddle River, NJ: Pearson Education.

Steger, M. F., Kashdan, T. B., Sullivan, B. A., \& Lorentz, D. (2008). Understanding the search for meaning in life: Personality, cognitive style, and the dynamic between seeking and experiencing meaning. Journal of Personality, 76(2), 199-228. https://doi.org/10.1111/j.1467-6494.2007.00484.x

Vella-Brodrick, D. A. (2013). Positive psychology interventions: Research evidence, practical utility, and future steps. Mental Well-Being. (pp. 331-353). New York, NY: Springer.

Waters, L. (2011). A review of school-based positive psychology interventions. The Australian Educational and Developmental Psychologist, 28(2), 75-90. https://doi.org/10.1375/aedp.28.2.75

Waters, L., \& White, M. (2015). Case study of a school wellbeing initiative: Using appreciative inquiry to support positive change. International Journal of Wellbeing, 5(1). https://doi.org/10.5502/ijw.v5i1.2

Wright, T. A. (2003). Positive organizational behavior: An idea whose time has truly come. Journal of Organizational Behavior, 24, 437-442. https://doi.org/10.1002/job.197 